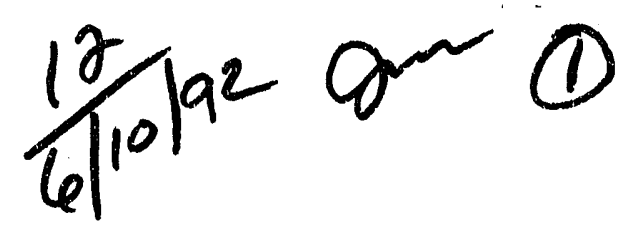

$\frac{\text { PNL-8089 }}{\text { UC-721 }}$

\title{
Hanford Ferrocyanide Waste Chemistry and Reactivity Preliminary Catalyst and Initiator Screening Studies
}
R. D. Scheele
J. M. Tingey
S. A. Bryan
L. L. Burger
J. W. Johnston
R. T. Hallen

May 1992

Prepared for the U.S. Department of Energy under Contract DE-AC06-76RLO 1830

Pacific Northwest Laboratory

Operated for the U.S. Department of Energy

by Battelle Memorial Institute

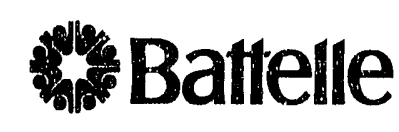




\title{
DISCLAIMER
}

This report was prepared as an account of work sponsored by an agency of the United States Government. Neither the United States Government nor any agency thereof, nor Battelle Memorial Institute, nor any of their employees, makes any warranty, expressed or implied, or assumes any legal liability or responsibility for the accuracy, completeness, or usefulness of any information, apparatus, product, or process disclosed, or represents that its use would not infringe privately owned rights. Reference herein to any specific commercial product, process, or service by trade name, trademark, manufacturer, or otherwise does not necessarily constitute or imply its endorsement, recommendation, or favoring by the United States Governinent or any agency thereof, or Battelle Memorial Institute. The views and opinions of authors expressed herein dio not necessarily state or reflect those of the United States Government or any agency thereof.

\author{
PACIFIC NORTHWEST LABORATORY \\ operated by \\ BATTELLE MEMORIAL INSTITUTE \\ for the \\ UNITED STATES DEPARTMENT OF ENERGY \\ unter Contract DE-ACO6-76RLO 1830
}

Printed in the United States of America

Available to DOE and DOE contractors from the

Office of Scientific and Technical Information, P.O. Box 62, Oak Ridge, TN 37831; prices available from (615) 576-8401. FTS 626-8401.

Available to the public from the National Technical Information Service, U.S. Department of Commerce, 5285 Port Royal Rd., Springfield, VA 22161. 


\section{HANFORD FERROCYANIDE WASTE CHEMISTRY AND REACTIVITY PRELIMINARY CATALYST AND \\ INITIATOR SCREENING STUDIES}
R. D. Scheele
S. A. Bryan
J. W. Johnston
J. M. Tingey
L. L. Burger
R. T. Hallen

May 1992

Prepared for

the U.S. Department of Energy

under Contract DE-AC06-76RLO 1830

Pacific Northwest Laboratory

Richland, Washington 99352

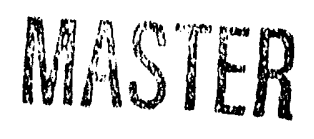




\section{SUMMARY}

During the 1950s, ferrocyanide was used to scavenge radiocesium from aqueous nitrate-containing Hanford wastes. During the production of defense materials and while these wastes were stored in high-level waste tanks at the Hanford Site, some of these wastes were likely mixed with other waste constituents and materials. Recent7y, Pacific Northwest Laboratory (PNL) was commissioned by Westinghouse Hanford Company (WHC) to investigate the chemical reactivity of these ferrocyanide-bearing wastes. Because of known or potential thermal reactivity hazards associated with ferrocyanide." and nitratebearing wastes, and because of the potential for different materials to act as catalysts or initiators of the reactions about which there is concern, we at PNL have begun investigating the effects of the other potential waste constit. uents. This report presents the results of a preliminary screening study to identify classes of materials that might be in the Hanford high-level waste tanks and that could accelerate or reduce the starting temperature of the reaction(s) of concern. We $\mathrm{plan}$ to use the results of this study to determine which materials or class of materials merit additional research.

Our preliminary study employed a statistically based experimental design and PNL's time-to-explosion (TTX) test to investigate the effects of tetrasodium ethylenediaminetetraacetate (EDTA) and the hydroxides of iron, chromium (III), and nickel on the reaction between sodium nickel ferrocyanide and equimolar sodium nitrate and nitrite. These selected potential catalysts and initiators were tested individually and in their possible combinations (also termed treatments), each at 0.03 mole per mole of ferrocyanide in a. mixture of sodium nickel ferrocyanide and equimolar sociium nitrate and nitrite. The amount of nitrate and nitrite in the tested mixtures was 1.1 times the stoichiometric amount needed for the most energetic reactions.

The test results suggest that many of the treatments lowered the TTX at each of the test temperatures; however, only a few treatments lowered the TTX sufficiently to cause a statistically significant effect at the $95 \%$ confidence level. At $380^{\circ} \mathrm{C}$, these treatments were EDTA alone; the combination of EDTA, 
iron hydroxide, and chromium hydroxide; and the combination of all the materials. At $350^{\circ} \mathrm{C}$, the combination of EDTA and iron hydroxide caused a statistically significant reduction. Note that EDTA was present in each of these mixtures. At $320^{\circ}$ and $296^{\circ} \mathrm{C}$, no treatment significantiy reduced the TTX, nor did any of the treatments reduce the minimum observed explosion temperature of $293 \pm 3^{\circ} \mathrm{C}$. We hypothesize that possibly oxidation of the EDTA first provided additional heat to the system, or that EDTA complexed with the sodium nickel ferrocyanide to destabilize the compound and increase the susceptibility to oxidation by nitrate or nitrite.

This screening study suggests that materials such as EDTA or other organic complexants will have the greatest catalytic or initiating effect on the reaction between sodium nickel ferrocyanide and nitrate and/or nitrite, though there are indications that the transition metal hydroxides work in conjunction with EDTA or could enhance EDTA's effect. At a minimum, future studies should focus on EDTA and probably should include one or two of the transition metal hydroxides we tested; other organic complexants should also be evaluated. 
CONTENTS

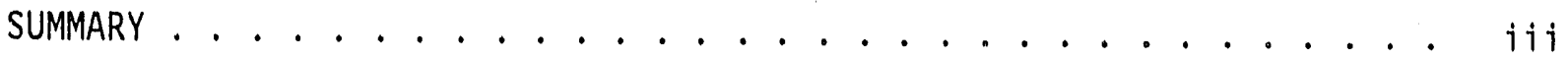

1.0 INTRODUCTION . . . . . . . . . . . . . . . . . . 1.1

1.1 SOURCE AND NATURE OF HANFORD FERROCYANIDE-

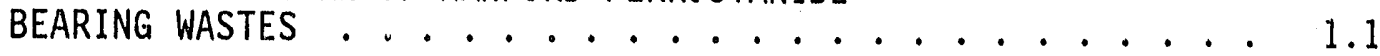

1.2 SELECTION OF CATALYSTS AND INITIATORS FOR TESTING $\ldots \ldots$.

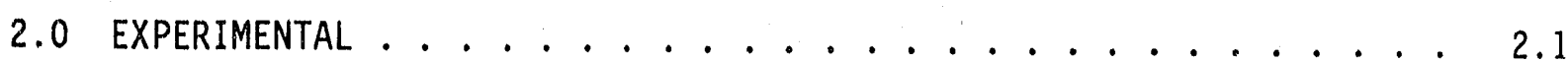

2.1 PREPARATION OF MATERIALS ............. 2.1

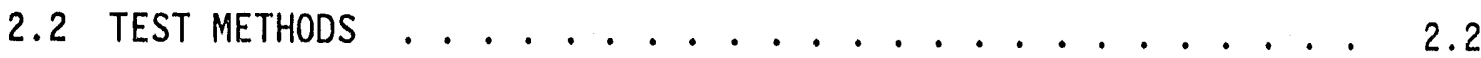

2.3 EXPERIMENTAL DESIGN $\ldots \ldots \ldots \ldots$

3.0 RESULTS OF SCREENING STUDY . . . . . . . . . . . 3.1

3.1 PRELIMINARY DISCUSSION OF RESULTS $\ldots \ldots \ldots \ldots . \ldots . \ldots . \ldots$

3.2 IDENTIFICATION OF POTENTIAL CATALYST/INITIATORS $\ldots \ldots .3 .5$

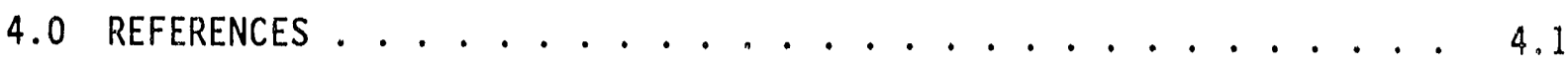

APPENDIX A - TTX RESULTS OF FIRST C/I SCREENING STUDY . . . . . . . . A.I

$\begin{aligned} \text { APPENDIX B } & \text { PLOT OF } 95 \% \text { CONFIDENCE LIMITS BASED ON DUNNETT } \\ & \text { DIFFERENCE FROM CONTROL . . . . . . . . . . . . . . . } 1\end{aligned}$ 


\section{FIGURES}

1 Arrhenius-Type Plot for $\ln (T T X)$ versus Reciprocal Temperature for a Mixture of Sodium Nickel Ferrocyanide and Equimolar

Sodium Nitrate and Nitrite . . . . . . . . . . . . 3.2

2 DSC Analysis of Reaction(s) Between $\mathrm{Na}_{2} \mathrm{NiFe}(\mathrm{CN})_{6}$ and Equimolar Sodium Nitrate and Nitrite . . . . . . . . . 3.3

3 STG Analyses of Reaction(s) Between $\mathrm{Na}_{2} \mathrm{NiFe}(\mathrm{CN})_{6}$ and Equimolar Sodium Nitrate and Nitrite ........... 3.4

$4 \mathrm{~N}_{2}$ and/or CO Produced from Temperature Programmed Pyrolysis of $\mathrm{Na}_{2} \mathrm{NiFe}(\mathrm{CN})_{6}$ and Equimolar Sodium Nitrate and Nitrite Mixture ................. 3.4

5 Effect of Treatments on Mean $\ln (T T X)$ at Different Temperatures ................... 3.6

6 Effect of Treatments on Mean $1 n(T T X)$ at $380^{\circ} \mathrm{C}$ Including 95\% Confidence Limits Based on Dunnett Difference from Control ................... 3.8

\section{TABLES}

1 Composition of Tested Samples .............. 2. . . . 3

2 Effect of Treatment on Mean $\ln (T T X)$. . . . . . . . . 3.7

3 In(TTX) Means and Dunnett-Based 95\% Confidence Limits Transformed Back to Seconds .............. . 3.10 


\subsection{INTRODUCTION}

\subsection{SOURCE AND NATURE OF HANFORD FERROCYANIDE-BEARING WASTES}

At the Hanford Site during the 1950s, radiocesium was scavenged from aqueous radioactive wastes containing nitrate by precipitating alkali nickel ferrocyanides. In some cases, the aqueous wastes contained large quantities of dissolved solids that precipitated during the decontamination treatments, potentially mixing with the ferrocyanide solids. In other cases, the process likely resulted in ferrocyanide solids free of other insoluble solids. The radiocesium scavenging campaigns were often coupled with other processes to scavenge other radionuclides, thus producing solid wastes containing other radionuclides and chemicals.

The ferrocyanide wastes have been stored in Hanford's single-shell tanks (SSTs) for over 30 years. During that time, these wastes were heated to evaporate excess solution, and concentrated and hot wastes were added to the ferrocyanide-containing tanks. The ferrocyanide wastes were moved to other tanks and exposed to high levels of radiation and to $\mathrm{pH}$ levels above 7 . A11 of these normal tank management activities and environmental exposures have potentially caused different materials to be added to the original ferrocyanide-bearing wastes. These additional materials include organic complexants (Klem 1990), transition metal hydroxides, sulfides, calcium or strontium phosphates, chlorides, fission product oxides or hydroxides (Scheele et a1. 1992). The organic complexants and sulfides are themselves susceptible to rapid oxidation by nitrates and nitrites and could act as initiators or catalysts for the ferrocyanide reaction with nitrate and nitrite. Transition metals, which will be in the wastes as results of fisition or corrosion, are known to act as catalysts for some reactions.

Because of concerns about the safe storage of these wastes (Burger 1984; Peach 1991), Westinghouse Hanford Company (WHC, the operating contractor for the Hanford Site) has chartered Pacific Northwest Laboratory $(\mathrm{PNL})^{(\mathrm{a})}$ to

(a) Pacific Northwest Laboratory is operated by Battelle Memorial Institute for the U.S. Department of Energy under Contract DE-ACO6-76RLO 1830. 
investigate the reactivity and explosivity of ferrocyanide wastes. As part of these reactivity studies, we at PNL are investigating the effects of waste constituents that could have been mixed with the precipitated ferrocyanides. Our objective in this study is to identify candidate waste constituents that may act as catalysts or initiators; to do so, we performed a preliminary study to screen selected classes of materials that might be in the Hanford highlevel waste (HLW) tanks. We plan to use the results of this preliminary study to determine which materials or class of materials merit additional study. This report specifically discusses the results of our preliminary screening studies using the PNL time-to-explosion (TTX) test coupled with statistically based analytical methods to identify the material or combination of materials that cause a reduction in the TTX.

\subsection{SELECTION OF CATALYSTS AND INITIATORS FOR TESTING}

In our previous studies to determine the effects of potential catalysts and initiators on the thermal reaction between cesium nickel ferrocyanide and equimolar sodium nitrate and nitrite, we used the TTX test to investigate tetrasodium ethylenediaminetetraacetate (EDTA), a mixture of tributyl phosphate and normal paraffin hydrocarbon (TBP/NPH), ferric hydroxide, nickel hydroxide, ammonium nitrate, and sodium hydroxide at the 5 mol\% level in the oxidant. Ferric hydroxide, nickel hydroxide, and EDTA reduced the explosion times and the minimum explosion temperatures. EDTA had the greatest effect, causing a reduction in the minimum explosion temperature from $350^{\circ}$ to $280^{\circ} \mathrm{C}$. The other compounds had minimal effects (Burger and Scheele 1991).

Based on our previous results and on our discussion with M. J. Klem of WHC regarding other materials that are likely to be or have been obcrived in the SST wastes, we selected EDTA, and ferric, nickel, and chromium (III) hydroxides (abbreviated $E, F, N$, and $C$, respectively) for our preliminary studies to determine catalysts and initiators for the reaction between sodium nickel ferrocyanide and sodium nitrate and nitrite. We also decided to use a catalyst and/or initiator ratio of 0.03 mole per mole of sodium nickel ferrocyanide. 


\subsection{EXPERIMENTAL}

The effects of four potential catalysts or initiators on the reactions of sodium nickel ferrocyanide with an equimolar mix of sodium nitrate and sodium nitrite were studied using a modified Henkin test. All the materials used in these studies were prepared at PNL except for the EDTA, which was purchased from a commercial vendor. This section of the report contains a description of the preparation of the materials, test methods, and the experimental design.

\subsection{PREPARATION OF MATERIALS}

The scavenging of radiocesium from the aqueous Hanford wastes was accomplished by adding $\mathrm{K}_{4} \mathrm{Fe}(\mathrm{CN})_{6}$ (or the sodium analog) to the aqueous waste, adjusting the $\mathrm{pH}$ to about 9 , and adding $\mathrm{NiSO}_{4}$ at a concentration equal to the ferrocyanide. The ferrocyanide compound used in the studies described in this report was prepared in a similar manner and washed to remove the soluble salts to provide a relatively pure sodium nickel ferrocyanide.

To prepare the sodium nickel ferrocyanide for this study, sodium ferrocyanide $\left[\left(\mathrm{Na}_{4} \mathrm{Fe}(\mathrm{CN})_{6} \cdot 10 \mathrm{H}_{2} \mathrm{O}\right)\right](0.17 \mathrm{M})$ was dissolved in an aqueous solution with a high ionic strength $\left(1.7 \mathrm{M} \mathrm{NaNO}{ }_{3}\right)$. This solution was agitated and heated to $80^{\circ} \mathrm{C}$, followed by the addition of $\mathrm{Ni}\left(\mathrm{NO}_{3}\right)_{2}(0.15 \mathrm{M})$. The solution was agitated for $1 \mathrm{~h}$ at $70^{\circ} \mathrm{C}$ and allowed to settle overnight at $60^{\circ} \mathrm{C}$. Only minimal settling occurred; therefore, the sample was centrifuged (ambient temperature), and the supernate was decanted. To produce a relatively pure sodium nickel ferrocyanide, the majority of the centrifuged solids were washed with water several times. In addition, a final wash was performed with a $0.03 \mathrm{M} \mathrm{Na}_{2} \mathrm{SO}_{4}$ solution at $\mathrm{pH} \mathrm{10}$. The washed solids were centrifuged, dried in a vacuum oven at $160^{\circ} \mathrm{C}$ and $10 \mathrm{w}$ vacuum $(<20 \mathrm{~mm} \mathrm{Hg})$, and ground with a mortar and pestle to -200 mesh.

Chemical analyses of the sodium nickel ferrocyanide sample were performed to determine the composition of the sample. The chemical arialyses performed included inductively coupled argon plasma atomic emission spectroscopy (ICP/AES) to measure elemental content, ion chromatography (IC) to 
measure anion content, $x$-ray diffraction spectroscopy (XRD) to identify specific chemical species, total cyanide, total carbon, and scanning thermogravimetric analysis (STG). The composition of this sample as determined by these methods was nominally $\mathrm{Na}_{2} \mathrm{NiFe}(\mathrm{CN})_{6} \cdot 3 \mathrm{H}_{2} \mathrm{O}$.

Three of the catalysts [iron (III), nickel (II), and chromium (III) hydroxides] were prepared from $3 \mathrm{M}$ solutions of $\mathrm{Fe}\left(\mathrm{NO}_{3}\right)_{3}, \mathrm{Ni}\left(\mathrm{NO}_{3}\right)_{2}$, and $\mathrm{Cr}\left(\mathrm{NO}_{3}\right)_{3}$. These solutions were titrated with $\mathrm{NaOH}$ to $\mathrm{pH} 13$ to precipitate the metals as hydroxide salts or as hydrous oxides. The precipitate was centrifuged and the supernate discarded. Chemical analyses of these salts indicated that their nominal compositions were $\mathrm{Cr}(\mathrm{OH})_{3} \cdot \mathrm{H}_{2} \mathrm{O}, \mathrm{FeO}(\mathrm{OH}) \cdot 2 \mathrm{H}_{2} \mathrm{O}$, and $\mathrm{Ni}(\mathrm{OH})_{2}$. EDTA, the fourth suspect catalyst and/or initiator, was purchased from a commercial chemical supply company as the tetrasodium salt (98\% purity).

The oxidant was prepared by mixing reagent grade $\mathrm{NaNO}_{2}$ and $\mathrm{NaNO}_{3}$ at a mole ratio of $1: 1$. The mix was placed in a $350^{\circ} \mathrm{C}$ oven for $2 \mathrm{~h}$. The molten salt was cooled to room temperature, and the resulting solid was ground to -200 mesh. The solids were placed, in a $60^{\circ} \mathrm{C}$ oven for $2 \mathrm{~h}$ and then stored in a desiccator.

The samples used for the TTX testing were prepared by mixing the catalyst/initiator $(C / I)$ with the oxidant, then mixing the sodium nickel ferrocyanide with the oxidant and $C / I$ mixture, using a slight excess of oxidant; i.e., 1.1 times the stoichiometric amount for the most energetic postulated reactions requiring 6 moles of $\mathrm{NaNO}_{3}$ or 10 moles of $\mathrm{NaNO}_{2}$ per mole of ferrocyanide (Scheele et a1. 1992). The composition of each of the sixteen different C/I test samples was selected to allow use of statistically based analytical methods to identify significant factors; the experimental design is discussed in more detail later in Section 2.3. The amount of each of the $\mathrm{C} / \mathrm{Is}$ was equivalent to $3 \mathrm{mo} 1 \%$ of the ferrocyanide. The concentration for each of the components in these samples is given in Table 1.

\subsection{TEST METHODS}

We used the PNL TTX test (Burger and Scheele 1991) to investigate the effects of selected potential catalysts and/or initiators on the reactivity 
TABLE 1. Composition of Tested Samples

Concentration, Mole Per Mole Ferrocyanide

\begin{tabular}{|c|c|c|c|c|c|c|c|}
\hline Treatment & $\mathrm{Na}_{2} \mathrm{NiFe}(\mathrm{CN})_{6}$ & $\mathrm{NaNO}_{3}$ & $\mathrm{NaNO}_{2}$ & $\mathrm{Cr}^{(\mathrm{a})}$ & $\mathrm{Fe}^{(\mathrm{a})}$ & $\mathrm{Ni}^{(\mathrm{a})}$ & EDTA $^{(b)}$ \\
\hline Control & 1 & 4.12 & 4.12 & 0 & 0 & 0 & 0 \\
\hline $\mathrm{E}$ & 1 & 4.12 & 4.12 & 0 & 0 & 0 & 0.033 \\
\hline N & 1 & 4.12 & 4.12 & 0 & 0 & 0.033 & 0 \\
\hline$E * N$ & 1 & 4.12 & 4.12 & 0 & 0 & 0.033 & 0.033 \\
\hline$F$ & 1 & 4.12 & 4.12 & 0 & 0.033 & 0 & 0 \\
\hline$E^{*} F$ & 1 & 4.12 & 4.12 & 0 & 0.033 & 0 & 0.033 \\
\hline$N * F$ & 1 & 4.12 & 4.12 & 0 & 0.033 & 0.033 & 0 \\
\hline$E * N * F$ & 1 & 4.12 & 4.12 & 0 & 0.033 & 0.033 & 0.033 \\
\hline c & 1 & 4.12 & 4.12 & 0.033 & .0 & 0 & c \\
\hline$C * E$ & 1 & 4.12 & 4.12 & 0.033 & 0 & 0 & 0.033 \\
\hline $\mathrm{N} * \mathrm{C}$ & 1 & 4.12 & 4.12 & 0.033 & 0 & 0.033 & 0 \\
\hline$E * N * C$ & 1 & 4.12 & 4.12 & 0.033 & 0 & 0.033 & 0.033 \\
\hline$F^{* C} \mathrm{C}$ & 1 & 4.12 & 4.12 & 0.033 & 0.033 & 0 & 0 \\
\hline$E * F * C$ & 1 & 4.12 & 4.12 & 0.033 & 0.033 & 0 & 0.033 \\
\hline$N * F * C$ & 1 & 4.12 & 4.12 & 0.033 & 0.033 & 0.033 & 0 \\
\hline$E * N * F * C$ & 1 & 4.12 & 4.12 & 0.033 & 0.033 & 0.033 & 0.033 \\
\hline
\end{tabular}

(a) Precipitated from $\mathrm{pH} 13$ solution as hydroxide or hydrous oxide. (b) Tetrasodium ethylenediamineacetate.

and explosivity of mixtures of sodium nickel ferrocyanide and sodium nitrate and ritrite. This section provides a brief description of the TTX test.

The PNL TTX test provides a rough method of measuring kinetic effects and determining relative explosivities of materials. Therefore, the test was chosen to investigate the effects of selected C/Is on the explosivity of mixtures of $\mathrm{Na}_{2} \mathrm{NiFe}(\mathrm{CN})_{6}$, nitrate, nitrites, and catalysts and initiators. In this test method, the ITX was measured as a function of temperature for small, 60- to $70-\mathrm{mg}$ quantities of the various mixtures (the amount of ferrocyanide remained constant). By measuring the time required for an explosion to occur at several temperatures, it was possible to extrapolate the plot of time 
versus temperature to the minimum explosion temperature or critical temperature, $T_{c}$, for that particular configuration and size.

For the TTX testing, a 5-mm-diameter test tube (a thin wall NMR tube) containing about $70 \mathrm{mg}$ of sample was placed into a fitted $2.75-\mathrm{cm}$-deep hole in a stainless steel right cylinder measuring $3.6-\mathrm{cm}$ diameter by $4-\mathrm{cm} \mathrm{ta} 11$. Another hole, adjacent to the first, was provided for a thermocouple. The cylinder, surrounded by an insulating block, was placed on a hot plate and heated to and maintained at the desired temperature by a temperature controller.

The sample was placed in the heated cylinder, and the time from insertion to explosion was measured and recorded along with any visual observations. An explosion was defined : either a loud noise or a flash of light; often boih occurred. If no pronounced chemical reaction occurred within nominally $30 \mathrm{~min}$, the test was stopped. The test performed using the standard TTX procedure can be considered as a modified Henkin test (Henkin and McGi11 1952 ; Caldwel1 et a1. 1984; Faubian 1984).

In the TTX test, the TTX should be dependent on the temperature as would be predicted by the Arrhenius equation if a single reaction mechanism occurs. Often an explosion occurred after a period of a few seconds, but occasionally some occurred after $25 \mathrm{~min}$. Only one test, at $296^{\circ} \mathrm{C}$, did not explode after $30 \mathrm{~min}$. The absence of an explosion did not mean an exothermic reaction did not occur. Gases that were normally evolved during the testing of ferrocyanide and nitrate and/or nitrite mixtures included oxides of nitrogen (identified by the characteristic brown color of $\mathrm{NO}_{2}$ produced either just above the reaction mixture or slightly higher after the NO had an opportunity to react with air), and often the contents of the tube were splattered at lower temperatures.

\subsection{EXPERIMENTAL DESIGN}

To identify the materials or combination of materials that acted as catalysts or initiators, we selected an experimental design that would allow us to use statistically based analytical methods. The design of this $C / I$ study was based on partial replication of a full factorial experiment in a 
randomized block design. The factors investigated were the four $\mathrm{C} / \mathrm{Is}$ at two concentration levels, 0 and 0.03 mole per mole of ferrocyanide, and the temperature of the experimental apparatus. The compositions of the $15 \mathrm{c} / \mathrm{I}$ treatment and control test mixtures resulting from this experimental design are presented in Table 1.

Each of the treatments was tested at four different temperatures (nominal levels of $296^{\circ}, 320^{\circ}, 350^{\circ}$, and $380^{\circ} \mathrm{C}$ ) lising four distinct apparatus to allow the four tests to run concurrently. This design produced 64 distinct treatments when the $16 \mathrm{C} / \mathrm{I}$ mixtures were tested at each of the four temperatures.

Each of the 15 possible C/I treatments plus the control were randomly sequenced with replication of some of the treatments. The randomizision scheme allocated the treatments to the 33 tests performed on the first day so that:

- each $\mathrm{C} / \mathrm{I}$ treatment with a single $\mathrm{C} / \mathrm{I}$ was tested at three temperatures (12 tests)

- three of the mixtures with two $\mathrm{C} /$ Is were tested at two temperatures, and three were tested at one ( 9 tests)

- the mixtures with three $\mathrm{C} / \mathrm{Is}$ were tested at one temperature (4 tests)

- the mixture with all four C/Is was tested at two temperatures, (2 tests)

- the control, $\mathrm{Na}_{2} \mathrm{NiFe}(\mathrm{CN})_{6}$ sans $\mathrm{C} / \mathrm{I}$, was tested at three temperatures; once at $380^{\circ} \mathrm{C}$, twice at $320^{\circ} \mathrm{C}$, and three times at $350^{\circ} \mathrm{C}(6$ tests).

Each experimental apparatus was held at its assigned temperature throughout the 33 tests performed on the first day. The same order for the C/I treatments was maintained in all four sets of 33 tests with the temperatures randomly assigned to the individual experimental apparatus. A total of 132 tests were performed during the four days of study.

The expected marked differences in the TTX at the various temperatures should make irrelevant any lack of independence that may have resulted from following the same testing sequence of the $\mathrm{C} / \mathrm{I}$ in each subset of 33 tests. 


\subsection{RESULTS OF SCREENING STUDY}

This section presents and discusses the results of our first screening study to identify catalysts and/or initiators for the thermal reaction between ferrocyanide and nitrate and nitrite. In this study we used the PNL TTX test and designed the experiments such that statistical methods could be used to determine whether EDTA $(\mathrm{E}), \mathrm{Ni}(\mathrm{OH})_{2}(\mathrm{~N}), \mathrm{Fe}_{2} \mathrm{O}_{3}(\mathrm{~F})$, or $\mathrm{Cr}(\mathrm{OH})_{3}(\mathrm{C})$, and a 11 their possible combinations reduced the TTX at four discrete temperatures, ranging from $295^{\circ}$ to $380^{\circ} \mathrm{C}$, of a mixture of $\mathrm{Na}_{2} \mathrm{NiFe}(\mathrm{CN})_{6}$ and a stoichiometric amount of equimolar sodium $\mathrm{NaNO}_{3}$ and $\mathrm{NaNO}_{2}$.

The full set of test data is presented in Appendix A. Table A.1 1 ists the treatments in their natural order, along with their resulting TTX in seconds at each temperature. No statistical analysis was performer to determine whether the testing order (test number) and the experimental apparatus affected the TTX.

In addition to using statistical anal"ical methods, we conducted a very small study to determine the minimum explosion temperature for the different treatments using the sample size and geometry of our TTX test. In this study the treatments did not change the explosion temperature relative to the control. The minimum explosion temperature $\mathrm{fc}$ 'this geometry and sample size was $293^{\circ} \pm 3^{\circ} \mathrm{C}$ independent of treatment.

\subsection{PRELIMINARY DISCUSSION OF F TSULTS}

In early TTX testing, Burger and Scheele (1991) found a bilinear relationship between the natural $\log$ of the TTX, $\ln (T T X)$, and the inverse of the absolute temperature $(1 / T)$. If the explosive reaction is a single reaction that follows expected Arrhenius kinetic behavior, a linear relationship between $\ln (T T X)$ and $1 / T$ should be observed instead of the bilinear relationship observed in Figure 1, which presents a plot of $\ln (T T X)$ versus $1 / T$ for the control mixture and is typical of most of the other mixtures.

A bilinear relationship is one that is linear with one slope over part of the range and another slope over the other part of the range. The intersection of the two lines is referred to as the inflection point. The 


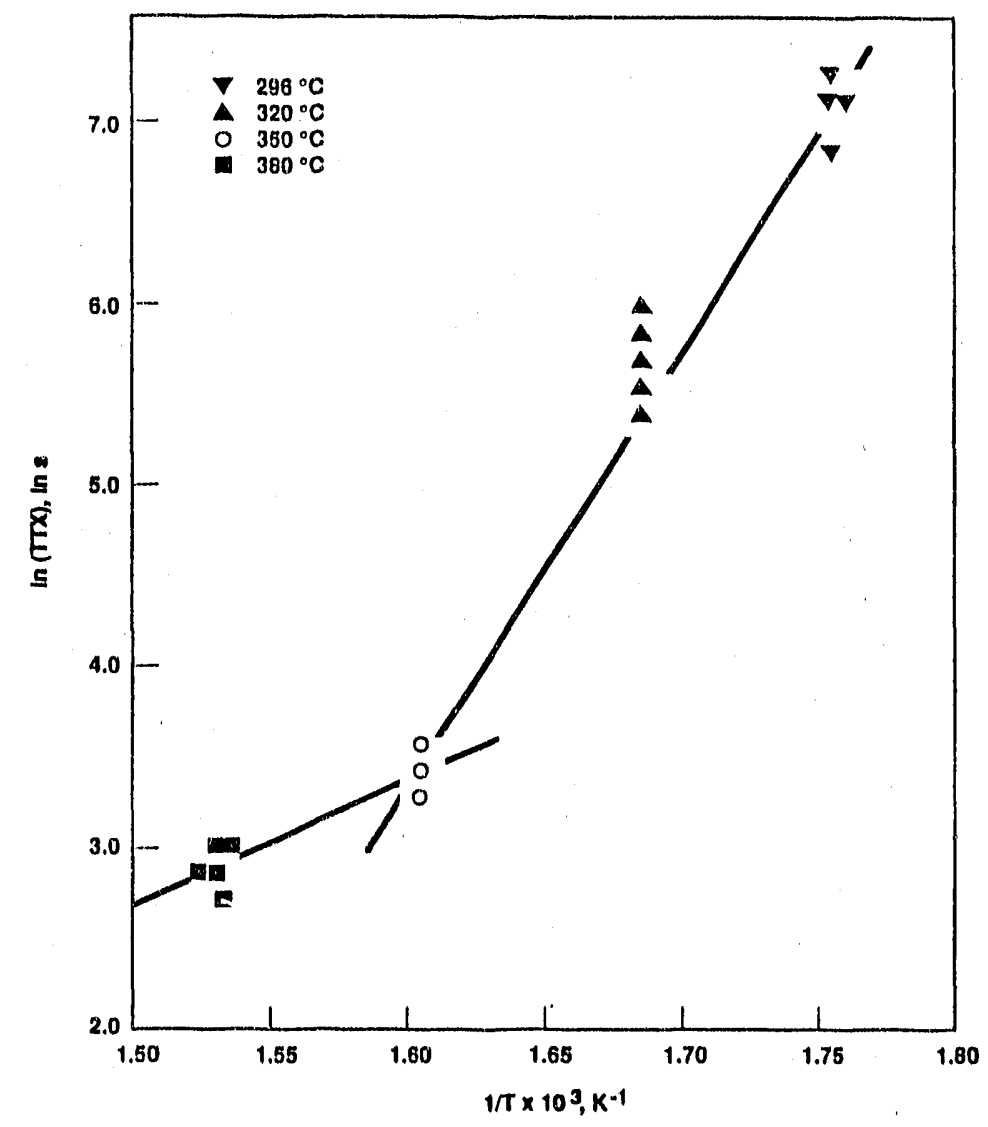

39203003,2

EIGURE 1. Arrhenius-Type Plot for In(TTX) versus Reciprocal Temperature for a Mixture of Sodium Nickel Ferrocyanide and Equimolar Sodium Nitrate and Nitrite (control)

inflection point in Figure 1 is near $1 / T$ of $1.6 \times 10^{-3}$ or at a temperature of $350^{\circ} \mathrm{C}$, which is near that observed for most treatments. An inflection point could be caused by a change in chemical mechanism for the explosion, or it might be explained by the relative time for heat transfer into the sample compared to the TTX.

The hyfithesis of a change in chemical mechanism is supported by the differential scanning calorimetry (DSC) analysis of the control mixture presented in Figure 2. According to this figure, several discrete reactions occur as the sample is heated to increasing temperatures or the oxidation of sodium nickel ferrocyanide by sodium nitrate and nitrite is a multistep 


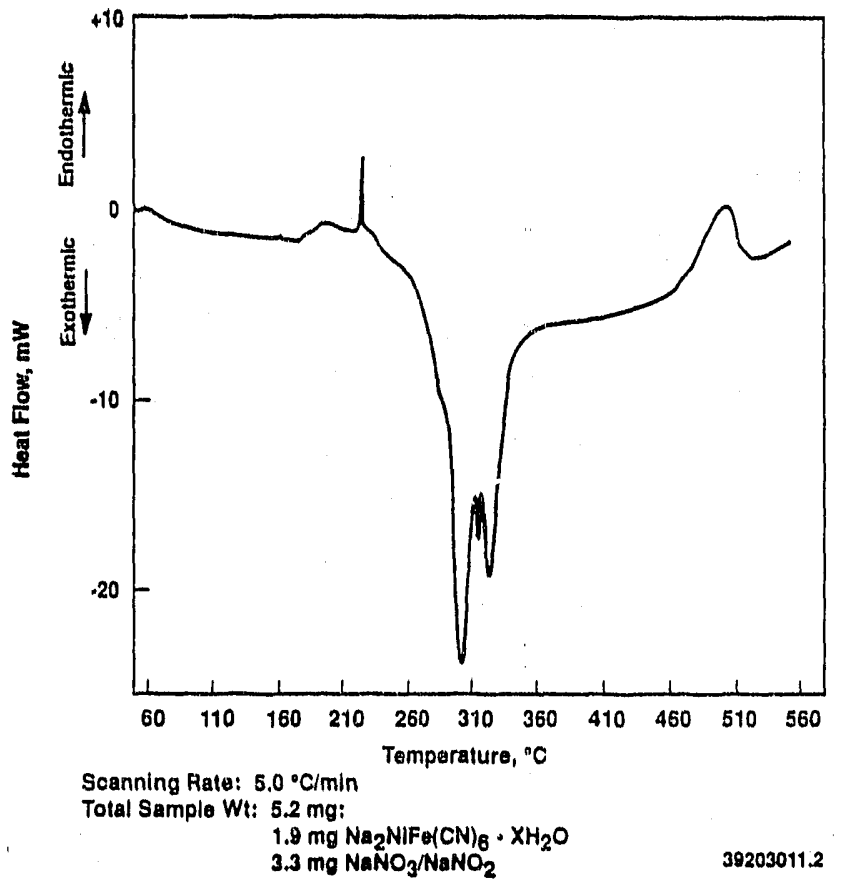

FIGURE 2. DSC Analysis of Reaction(s) Between $\mathrm{Na}_{2} \mathrm{NiFe}(\mathrm{CN})_{6}$ and Equimolar Sodium Nitrate and Nitrite (control)

reaction. Our STG results (Figure 3 ) and our initial mass spectral analysis of the released mass 28 gases from the control shown in Figure 4 (Scheele et a1. 1992) also indicate there are discrete temperature regimes for production of product gases. These observations suggest that a singular reaction will not predominate throughout the entire temperature range used in the TTX testing.

A second possible explanation for the data at $380^{\circ} \mathrm{C}$ to have exhibited different behavior than the rest of the data in Figure 1 could involve the physical heating of the reaction material. There is a time lag between the moment a sample tube is placed within the heated block and the time the reactants have equilibrated at the block temperature. At the very short TTXs measured for the $380^{\circ} \mathrm{C}$ data, this time 1 ag could represent a very significant fraction of the TTX value.

In earlier studies using $\mathrm{Cs}_{2} \mathrm{NiFe}(\mathrm{CN})_{6}$ to determine a time-temperature profile, we inserted a micro thermocouple into the test mixture and monitored temperature and time using a strip chart recorder. We encountered problems 


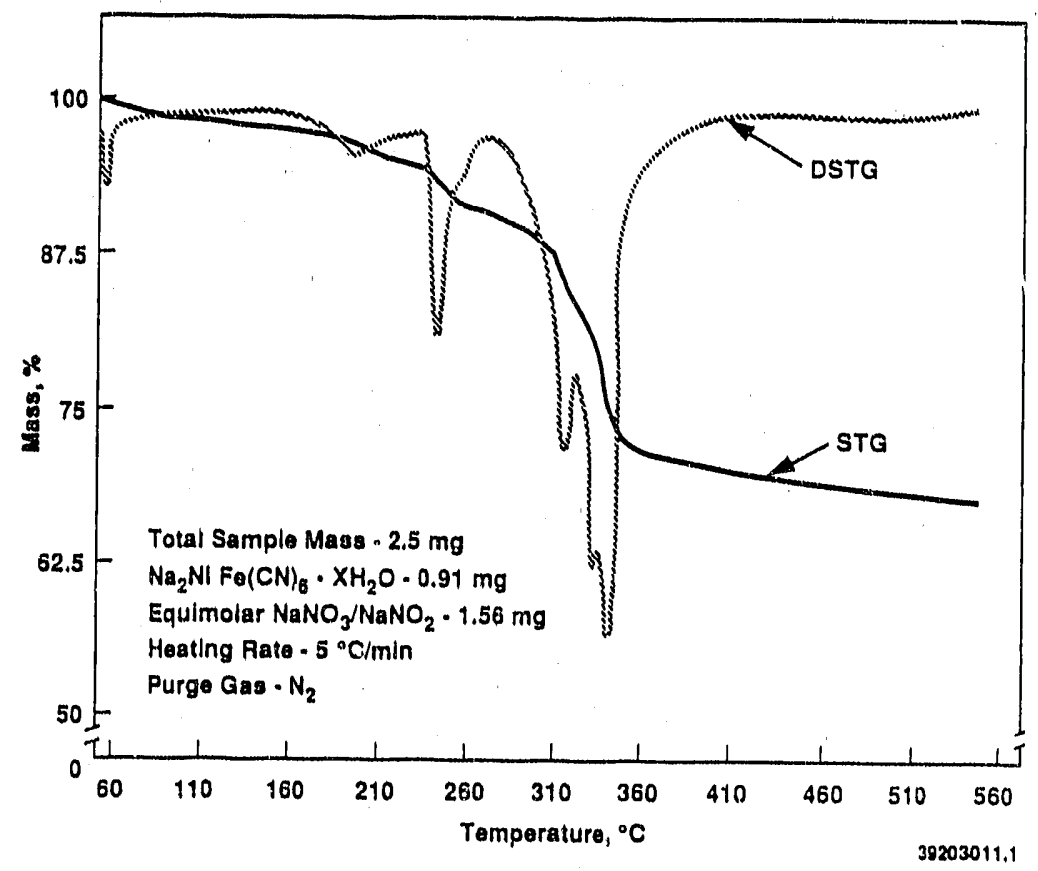

FIGURE 3. STG Analyses of Reaction(s) Between $\mathrm{Na}_{2} \mathrm{NiFe}(\mathrm{CN})_{8}$ and Equimolar Sodium Nitrate and Nitrite (control)

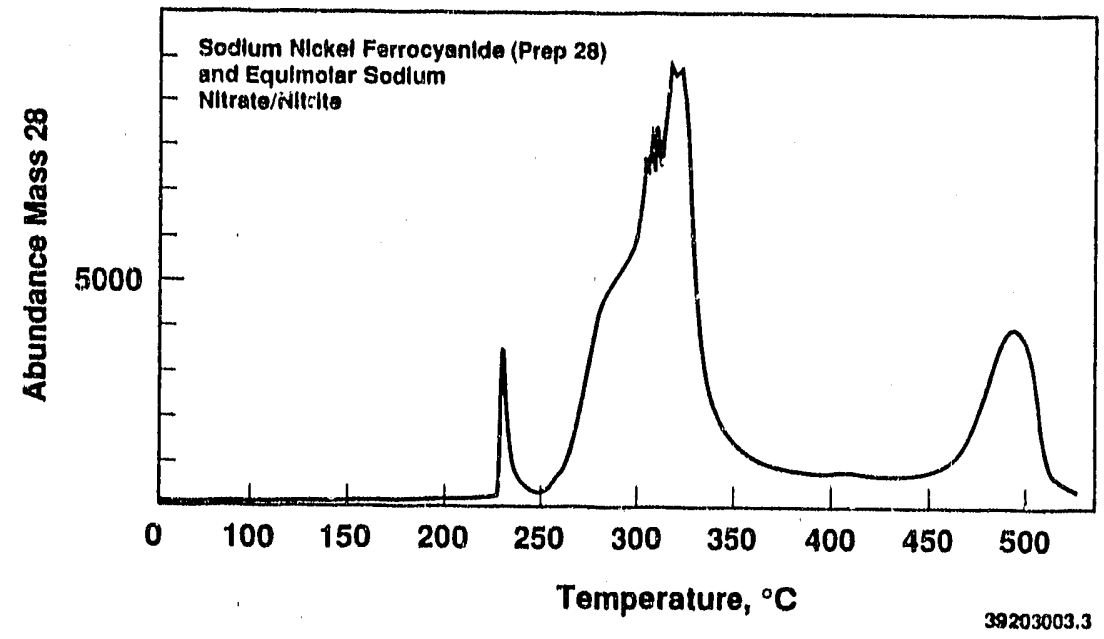

FIGURE 4. $\quad N_{2}$ and/or CO Produced from Temperature Programmed Pyrolys is of $\mathrm{Na}_{2} \mathrm{NiFe}(\mathrm{CN})_{6}$ and Equimolar Sodium Nitrate and Nitrite

Mixture (Scheele et a1. 1992) 
because of the small sample size and the excellent thermal conductivity of the thermocouples. The thermocouples transferred heat out of the system very rapidly, thus causing overestimation of the time to reach temperature.

Beczuse of our difficulties in measuring the actual time to temperature and explosion, we estimated the time to temperature and adjusted the TTX by different constant amounts. Even with this adjustment, the bilinear relationship between $\ln ($ TTX) and $1 / T$ continued to exist indicating that the time $1 \mathrm{ag}$ hypothesis is not an adequate explanation for the bilinear relationship.

Not 211 of the plots of $\ln ($ TTX) versus $1 / T$ produced a bilinear relationship. The exceptions to this apparent bilinear behavior are the plots of treatmerits $E^{*} F, E^{*} C, E^{*} N^{*} C$, and perhaps $N^{*} F * C$. All these exceptions are for treatments having only one observation at each temperature and, therefore, less reliable response patterns over temperature than the treatments with some replication. These plots also show that the data were well behaved, with no obvious outliers.

\subsection{IDENTIFICATION OF POTENTIAL CATALYST/INITIATORS}

This screening study was designed so that analysis of variance (AOV) methods could be used to analyze the results. The general linear models procedure (PROC GLM in the computer-based statistical analysis package SAS) was used to estimate the means and variances and to provide significance tests and confidence limits for testing the null hypothesis that there were no significant catalytic or initiator effects.

The first AOV model investigated was the full model with the five factors: nominal temperature (TG), E, N, F, and $C$ and the two-, three-, four-, and five-factor interactions that could be formed from them. This analysis indicated that the main effects for $T G, E$ and $F$, and the two-factor interactions $T G * E, E * C$ and $F * C$ had a statistically significant effect on the TTX (at least at the 95\% confidence level). The only higher order interaction that was statistically significant was $T G^{*} E^{*} C$.

This AOV also showed that the mean TTX at one temperature is statistically different from the mean TTX at each of the other temperatures as shown 
in Figure 5. This result would be predicted assuming Arrhenius kinetic behavior with the rate constant inversely proportional to the exponential of reciprocal temperature.

Since the TG main effect accounted for $98 \%$ of the total variability in the data, and there were significant interactions involving TG, we analyzed the data using Dunnett's test (1955) to determine the effects of each of the $\mathrm{C} / \mathrm{Is}$ and their combinations at each temperature. Dunirett's test is used to compare several treatments with a control, which in this case is sodium nickel ferrocyanide with equimolar sodium nitrate and nitrite. Dunnett's test maintains $95 \%$ confidence ( $<5 \%$ chance of judging a difference significant when it is not significant) for all comparisons made within a temperature level.

Because of expected Arrhenius behavior, we used the natural logarithm of the TTX for this statistical analysis to identify which additives acted as

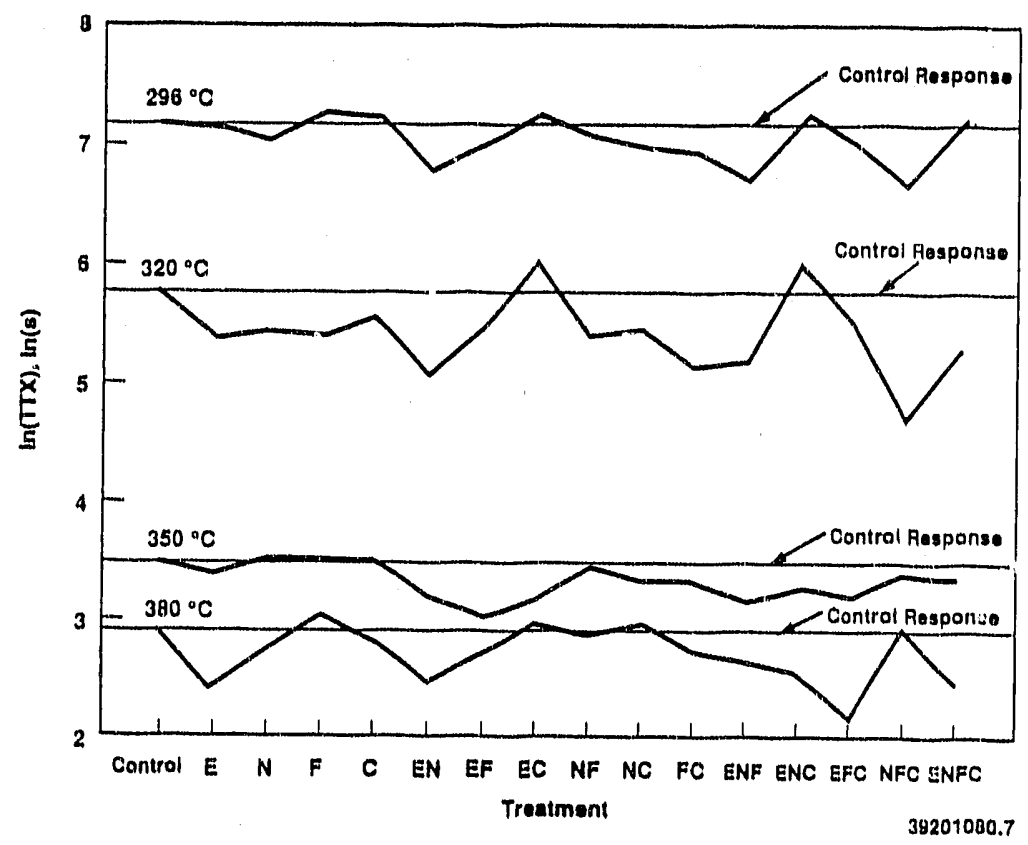

EIGURE 5. Effect of Treatments on Mean $\ln (T T X)$ at Different Temperatures $\left[E=E D T A, N=N i(O H)_{2}, \quad F=F e(O H)_{3}, C=C r(O H)_{3}, E N=E D T A\right.$ plus $\mathrm{Ni}(\mathrm{OH})_{2}$ (as an example of treatment combinations)] 
catalyst and/or initiators. The mean $\ln (T T X) s$ for each treatment and for the cortrol at each temperature are presented in Table 2, and graphically compared in Figure 5.

To illustrate the effect of each C/I on the TTX at a particulai temperature in Figure 5 , we included a horizontal line marking the mean for the contro1 in each temperature group. The mean TTXs for many of the $\mathrm{C} / \mathrm{I}$ treatments

IABLE 2. Effect of Treatment on Mean $\ln (T T X)$

\begin{tabular}{|c|c|c|c|c|c|c|}
\hline \multirow[b]{2}{*}{ Treatment } & \multirow[b]{2}{*}{$\underline{N}^{(a)}$} & \multicolumn{4}{|c|}{ Mean $\ln (T T X), \ln (s)$} & \multirow{2}{*}{$\begin{array}{c}\text { Overall } \\
\text { Treatment } \\
\text { Mean }\end{array}$} \\
\hline & & $296^{\circ} \mathrm{C}$ & $320^{\circ} \mathrm{C}$ & $350^{\circ} \mathrm{C}$ & $380^{\circ} \mathrm{C}$ & \\
\hline Control & 6 & 7.13 & 5.71 & 3.40 & 2.91 & 4.79 \\
\hline $\begin{array}{l}\text { EDTA } \\
\mathrm{Ni}(\mathrm{OH})_{2} \\
\mathrm{Fe}(\mathrm{OH})_{3} \\
\mathrm{Cr}(\mathrm{OH})_{3}\end{array}$ & $\begin{array}{l}3 \\
3 \\
3 \\
3\end{array}$ & $\begin{array}{l}7.11 \\
7.01 \\
7.25 \\
7.21\end{array}$ & $\begin{array}{l}5.33 \\
5.37 \\
5.34 \\
5.49\end{array}$ & $\begin{array}{l}3.33 \\
3.45 \\
3.41 \\
3.42\end{array}$ & $\begin{array}{l}2.41^{(b)} \\
2.74 \\
3.03 \\
2.83\end{array}$ & $\begin{array}{l}4.55^{(b)} \\
4.64 \\
4.76 \\
4.74\end{array}$ \\
\hline $\begin{array}{l}E^{* N} \\
E^{*} F \\
E^{*} C \\
N * F \\
N * C \\
F * C\end{array}$ & $\begin{array}{l}1 \\
1 \\
1 \\
2 \\
2 \\
2\end{array}$ & $\begin{array}{l}6.75 \\
7.01 \\
7.23 \\
7.05 \\
6.96 \\
6.94\end{array}$ & $\begin{array}{l}5.02 \\
5.43 \\
5.97 \\
5.34 \\
5.42 \\
5.09\end{array}$ & $\begin{array}{l}3.14 \\
2.94(b) \\
3.09 \\
3.37 \\
3.28 \\
3.26\end{array}$ & $\begin{array}{l}2.48 \\
2.71 \\
2.94 \\
2.88 \\
2.97 \\
2.74\end{array}$ & $\begin{array}{l}4.35^{(b)} \\
4.52 \\
4.81 \\
4.66 \\
4.66 \\
4.50^{(b)}\end{array}$ \\
\hline $\begin{array}{l}E * N * F \\
E * N * C \\
E * F * C \\
N * F * C\end{array}$ & $\begin{array}{l}1 \\
1 \\
1 \\
1\end{array}$ & $\begin{array}{l}6.70 \\
7.20 \\
7.01 \\
6.65\end{array}$ & $\begin{array}{l}5.14 \\
5.99 \\
5.48 \\
4.68\end{array}$ & $\begin{array}{l}3.09 \\
3.22 \\
3.14 \\
3.33\end{array}$ & $\begin{array}{l}2.64 \\
2.56 \\
2.20^{(b)} \\
2.94\end{array}$ & $\begin{array}{l}4.39^{(b)} \\
4.74 \\
4.46 \\
4.40^{(b)}\end{array}$ \\
\hline$E * N * F * C$ & 2 & 7.14 & 5.27 & 3.31 & $2.52^{(b)}$ & 4.56 \\
\hline $\begin{array}{l}\text { Mean of Means } \\
\text { Weighted Mean }\end{array}$ & $\begin{array}{l}16^{(c)} \\
33^{(d)}\end{array}$ & $\begin{array}{l}7.02 \\
7.07\end{array}$ & $\begin{array}{l}5.38 \\
5.42\end{array}$ & $\begin{array}{l}3.26 \\
3.32\end{array}$ & $\begin{array}{l}2.72 \\
2.76\end{array}$ & $\begin{array}{l}4.60 \\
4.64\end{array}$ \\
\hline Error Std. Dev. & & 0.17 & 0.38 & 0.12 & 0.13 & 0.23 \\
\hline
\end{tabular}

(a) Number of treatment replications at each temperature.

(b) Mean is significantly (one-sided 95\% Confidence Levei) smaller than control using Dunnett's test for significant differences from control.

(c) Number of mearis.

(d) Number of observations for each temperature. 
are less than the control, indicating that many of the $\mathrm{C} / \mathrm{Is}$ reduce the TTX relative to the control. It is valuable to note that most of those treatments exhlbiting a TTX less than the control contain EDTA. However, when the statistical variation about the mean for a treatment is taken into consideration, there were few of the $\mathrm{C} /$ Is that had a statistically significant effect.

Using Dunnett's test, a total of four treatments were found to cause a statistically significant difference in the TTX relative to the control at a particular temperature. At the two lower temperatures, no statistically significant difference was found. For the $350^{\circ} \mathrm{C}$ treatments, only the difference for the $E^{*} F$ interaction was significant. At $380^{\circ} \mathrm{C}$, the treatments $E, E^{*} F * C$, and $E * N * F * C$ were determined to have significant catalytic or initiating effects.

Figure 6 illustrates graphically the statistical analysis of the data obtained at $380^{\circ} \mathrm{C}$. Figure 6 presents a comparison of the mean $\ln ($ TTX) for the

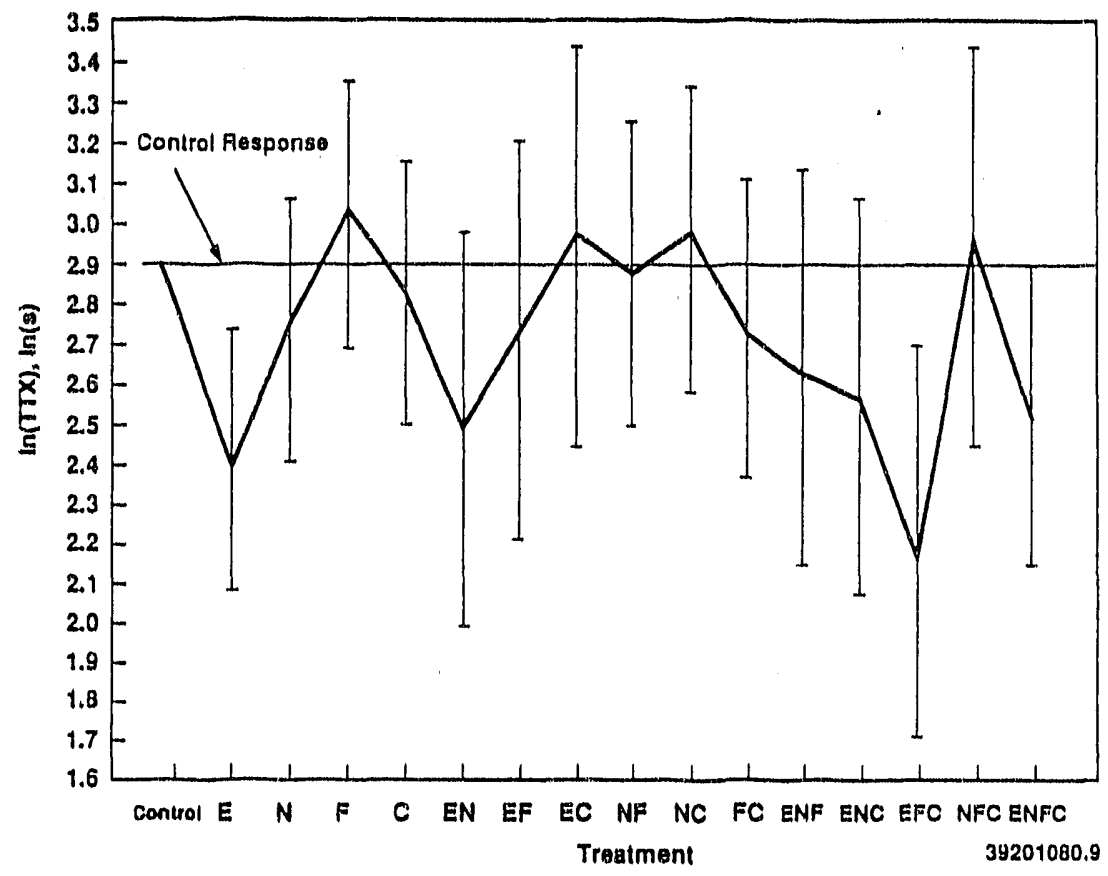

FIGURE 6. Effect of Treatments on Mean $\ln (\mathrm{TTX})$ at $380^{\circ} \mathrm{C}$ Including $95 \%$ Confidence Limits Based on Dunnett Difference from Control $\left[E=E D T A, N=\mathrm{Ni}(\mathrm{OH})_{2}, \mathrm{~F}=\mathrm{Fe}(\mathrm{OH})_{3}, \mathrm{C}=\mathrm{Cr}(\mathrm{OH})_{3}, \mathrm{EN}=\mathrm{EDTA}\right.$ plus $\mathrm{Ni}(\mathrm{OH})_{2}$ (as an example of treatment combinations)] 
control and the mean $\ln ($ TTX)s for the different treatments; included are the 95\% confidence intervals for the treatments. If a treatment had a statistically significant effect, the control's mean would be outside the treatment's confidence interva1. Using this criteria, Figure 6 shows that at $380^{\circ} \mathrm{C}$ the addition of EDTA alone, $E * F * C$, and $E * N * F * C$ caused a statistically significant reduction in the TTX. Similar presentations for the other three temperatures are presented in Appendix B, and they show the same results as reported in the previous paragraph.

The error standard deviation reported in Table 2 is the statistic that estimates the experimental variability. Based on the $\ln (T T X)$ units, the standard deviation for each temperature relative to the mean for that temperature is between $2 \%$ and $7 \%$, and when pooled over a 11 temperatures, it is about $5 \%$. This level of variability in the units of the statistical testing is not large for physical measurements such as the TTX.

Al1 these analyses were conducted using the $\ln (T T X)$. In an effort to gain additional information from our data, we transformed the $\ln$ (TTX) data presented in Table 2 back into time by computing their natural antilogarithm. The results of this back transformation appear in Table 3 , which presents the confidence limits and medians in seconds. Also given are the upper and lower half-widths (HW) for the $95 \%$ confidence 1 imits in seconds. This simple transformation is called the Naive Transformation by Land (1975). The Naive Transformation provides exact confidence limits for the median, thus resulting in confidence levels for the medians at somewhat 1ess than the $95 \%$ obtained for the natural log data. Because of the back transformation, the confidence limits in seconds are asymmetric (compare the upper and lower HW in rable 3 ).

Comparison of the medians of the control and treatments at each temperature presented in Table 3 yields the same results regarding statistically significant treatments as obtained using the $\ln (T T X)$. Again, the four treatments that caused reductions in the TTX were $E * F$ at $350^{\circ} C$ and $E, E^{*} F * C$, and $E^{*} N^{*} F * C$ at $380^{\circ} \mathrm{C}$.

The statistical analysis of the TTX test data indicates that only EDTA alone and the mixed treatments $E * F * C$ and $E * N * F * C$ at $380^{\circ} \mathrm{C}$, and $E * F$ at $350^{\circ} \mathrm{C}$ caused statistically significant (at the $95 \%$ confidence level) reductions in 
TABLE 3. $\ln (T T X)$ Means and Dunnett-Based 95\% Confidence Limits Transformed Back to Seconds

Temperature, 296

296

296

296

296

296

296

296

296

296

296

296

296

296

296

296

320

320

320

320

320

320

320

320

320

320

320

320

320

320

320

320

\begin{tabular}{l} 
Treatment \\
\hline$N^{*} F * C$ \\
$E^{*} N^{*} F$ \\
$E^{* N}$ \\
$E^{* * *} \mathrm{~F}$ \\
$E^{*} \mathrm{C}$ \\
$E^{*} N^{* C}$ \\
$E^{*} C$
\end{tabular}

$F * C$

$\mathrm{N} * \mathrm{C}$

$N \star F$

$E * N * F * C$

$N$
E
$C$
$F$

\section{Control}

$N * F * C$

$E * N$

$E * N * F$

$E * F$

$E * F * C$

$E * C$

$E * N * C$

$F * C$

$E * N * F * C$

$N * F$

$N * \mathrm{C}$

$\mathrm{E}$
$\mathrm{F}$
$\mathrm{N}$
$\mathrm{C}$

Control
Lower

Limit, $s$

415.10

438.25

460.32

597.01

597.61

724.13

741.90

646.88

660.48

725.22

786.20

735.99

814.13

902.07

941.68

6

-.

27.44

38.36

43.45

58.18

60.97

99.34

101.11

57.37

68.71

73.99

80.14

84.30

85.39

87.74

99.02

6
Upper

Median Limit, s

$771 \quad 1432.06$

814

855

1109

1110

1345

1378

1511.93

1588.08

2059.85

2061.73

2498.21

2559.51

1649.59

1684.24

1849.37

2007.35

1655.59

1831.37

2029.19

21.18 .30

1254.84

108

151

171

229

240

391

398

161.63

193.56

208.45

225.78

206.71

209.40

215.16

242.82

301.03
425.10

594.36

673.01

901.37

944.67

1539.03

1566.58

455.37

545.27

587.21

636.09

j06.91

513.49

527.63

595.46 
IABLE 3. (contd)

\begin{tabular}{|c|c|c|c|c|c|}
\hline $\begin{array}{c}\text { Temperature, } \\
{ }^{\circ} \mathrm{C}\end{array}$ & Treatment & $\underline{N}$ & $\begin{array}{l}\text { Lower } \\
\text { Limit, s } \\
\end{array}$ & Median & $\begin{array}{c}\text { Upper } \\
\text { Limit, s } \\
\end{array}$ \\
\hline $\begin{array}{l}350 \\
350 \\
350 \\
350 \\
350 \\
350 \\
350\end{array}$ & $\begin{array}{l}E^{*} F \\
E^{*} N * F \\
E^{*} C \\
E^{*} F * C \\
E^{* N} \\
E^{*} N * C \\
N * F * C\end{array}$ & $\begin{array}{l}1 \\
1 \\
1 \\
1 \\
1 \\
1 \\
1\end{array}$ & $\begin{array}{l}12.41 \\
14.37 \\
14.37 \\
15.03 \\
15.03 \\
16.33 \\
18.29\end{array}$ & $\begin{array}{l}19.00 \\
22.00 \\
22.00 \\
23.00 \\
23.00 \\
25.00 \\
28.00\end{array}$ & $\begin{array}{l}29.08 \\
33.67 \\
33.67 \\
35.21 \\
35.21 \\
38.27 \\
42.86\end{array}$ \\
\hline $\begin{array}{l}350 \\
350 \\
350 \\
350 \\
350 \\
350 \\
350 \\
350\end{array}$ & $\begin{array}{l}F * C \\
N * C \\
E * N * F * C \\
N * F \\
E \\
F \\
C \\
N\end{array}$ & $\begin{array}{l}2 \\
2 \\
2 \\
2 \\
3 \\
3 \\
3 \\
3\end{array}$ & $\begin{array}{l}18.83 \\
19.20 \\
19.93 \\
21.01 \\
21.15 \\
22.95 \\
23.17 \\
23.95\end{array}$ & $\begin{array}{l}25.98 \\
26.50 \\
27.50 \\
28.98 \\
27.95 \\
30.33 \\
30.62 \\
31.64\end{array}$ & $\begin{array}{l}35.84 \\
36.55 \\
37.93 \\
39.98 \\
36.94 \\
40.08 \\
40.46 \\
41.81\end{array}$ \\
\hline 350 & Control & 6 & -- & 29.94 & $\ldots$ \\
\hline $\begin{array}{l}380 \\
380 \\
380 \\
380 \\
380 \\
380 \\
380\end{array}$ & $\begin{array}{l}E * F * C \\
E * N \\
E * N * C \\
E * N * F \\
E * F \\
N * F * C \\
E * C\end{array}$ & $\begin{array}{l}1 \\
1 \\
1 \\
1 \\
1 \\
1 \\
1\end{array}$ & $\begin{array}{r}5.46 \\
7.28 \\
7.88 \\
8.49 \\
9.10 \\
11.52 \\
11.52\end{array}$ & $\begin{array}{r}9.00 \\
12.00 \\
13.00 \\
14.00 \\
15.00 \\
19.00 \\
19.00\end{array}$ & $\begin{array}{l}14.84 \\
19.79 \\
21.43 \\
23.08 \\
24.73 \\
31.33 \\
31.33\end{array}$ \\
\hline $\begin{array}{l}380 \\
380 \\
380 \\
380\end{array}$ & $\begin{array}{l}E * N * F * C \\
F * C \\
N * F \\
N * C\end{array}$ & $\begin{array}{l}2 \\
2 \\
2 \\
2\end{array}$ & $\begin{array}{r}8.50 \\
10.57 \\
12.16 \\
13.32\end{array}$ & $\begin{array}{l}12.41 \\
15.43 \\
17.75 \\
19.44\end{array}$ & $\begin{array}{l}18.11 \\
22.51 \\
25.90 \\
28.37\end{array}$ \\
\hline $\begin{array}{l}380 \\
380 \\
380 \\
380 \\
380\end{array}$ & $\begin{array}{l}\mathrm{E} \\
\mathrm{N} \\
\mathrm{C} \\
\mathrm{F} \\
\text { Control }\end{array}$ & $\begin{array}{l}3 \\
3 \\
3 \\
3 \\
6\end{array}$ & $\begin{array}{r}8.06 \\
11.12 \\
12.24 \\
14.88 \\
--\end{array}$ & $\begin{array}{l}11.19 \\
15.43 \\
16.98 \\
20.65 \\
18.29\end{array}$ & $\begin{array}{l}15.52 \\
21.40 \\
23.56 \\
28.64 \\
\ldots-\end{array}$ \\
\hline
\end{tabular}


the TTX. However, comparing the mean effect of each treatment to the control mean indicates that many of these suspect catalysts and/or initiators and their combinations reduce the TTX.

The common additive to all the statistically significant and most all the near-statistically significant treatments is IDTA. We do not know enough about the reaction mechanism to explain why the ferrocyanide and nitrate and nitrite reaction is accelerated by EDTA. The important role of EDTA in these reactions may be due to its hydrocarbon fuel content. At the high temperatures used in this study, it is possible for EDTA to react exothermically with the oxidants present in the test matrix. The heat liberated from this reaction could then initiate or accelerate the reaction of tile $\mathrm{Na}_{2} \mathrm{NiFe}(\mathrm{CN})_{6}$ with the oxidants. An alternative hypothesis is that the EDTA complexes with the nickel or iron in the sodium nickel ferrocyanide increasing the susceptibility of the carbon and nitrogen to oxidation by the nitrate or nitrite. 


\subsection{REFERENCES}

Burger, L. L. 1984. Complexant Stability Investigation Task 1 - Ferrocyanide

Solids. PNL-5441, Pacific Northwest Laboratory, Richland, Washington.

Burger, L. L., and R. D. Scheele. 1991. The Reactivity of Cesium Nickel Ferrocyanide Towards Nitrate and Nitrite Salts. PNL-7550, Pacific Northwest Laboratory, Richland, Washington.

Caldwe11, D. J., J. B. Edwards, and J. R. Keifer. 1984. "Use of Gasometric, Time-to-Explosion, and Isothermal Differential Scanning Calorimeter to Assess Compatibility of Double-Base Propellants and Epoxy Resin Systems." $\mathrm{J}$. Haz. Mater. 9:77.

Dunnett, C. W. 1955. "A Multiple Comparison Procedure for Comparing Several Treatments with a Control." J.Am. Statis. Assoc. 50:1096-1121.

Faubian, B. D. 1984. "Henkin One-Shot Test - A Statistical Approach for Estimating Critical Temperatures." J. Haz. Mater. 9:95.

Henkin, H., and R. McGill. 1952. "Rates of Explosive Decumposition of Explosives - Experimental and Theoretical Kinetic Study as a Function of Temperature." Ind. Eng. Chem. 44:1391.

Klem, M. J. 1990. Inventory of Chemicals Used at Hanford Site Production Plants and Support Operations (1944-1980). WHC-EP-0172 Rev. 1, Westinghouse Hanford Company, Richland, Washington.

Land, C. E. 1975. "An Evaluation of Approximate Confidence Interval Estimation Methods for Lognormal Means." Technometrics 14:145-158.

Peach, J. D. 1991. "Consequences of Explosion of Hanford's Single-Shell Tanks Are Understated." (Letter B-241479 to C. M. Synar, Chairman of Environment, Energy and Natural Resources Subcommittee, Committee on Government Operations, House of Representatives) GAO/RCED-91-34, General Accounting Office, Washington, D.C.

Scheele, R. D., L. L. Burger, S. A. Bryan, G. L. Borsheim, B. C. Simpson, R. J. Cash, and H. H. Cady. 1991. Ferrocyanide-Containing Waste Tanks: Ferrocyanide Chemistry and Reactivity. PNL-SA-19924, Pacific Northwest Laboratory, Richland, Washington.

Scheele, R. D., L. L. Burger, J. M. Tingey, R. T. Hallen, and M. A. Lilga. 1992. Chemical Reactivity of Potential Ferrocyanide Precipitates in Hanford Tanks with Nitrate and/or Nitrites. PNL-SA-19971, Pacific Northwest Laboratory, Richland, Washington.

Twigg, M. V. 1989. Catalyst Handbook. Wolfe Publishing Ltd., London. 
APPENDIX A

ITX RESULTS OF FIRST C/I SCREENING STUDY 
IABLE A.1. TTX Results of First Catalyst and/or Initiator (C/I) Screening Study for Reaction Between Sodium Nickel Ferrocyanide and Equimolar Sodium Nitrate and Nitrite

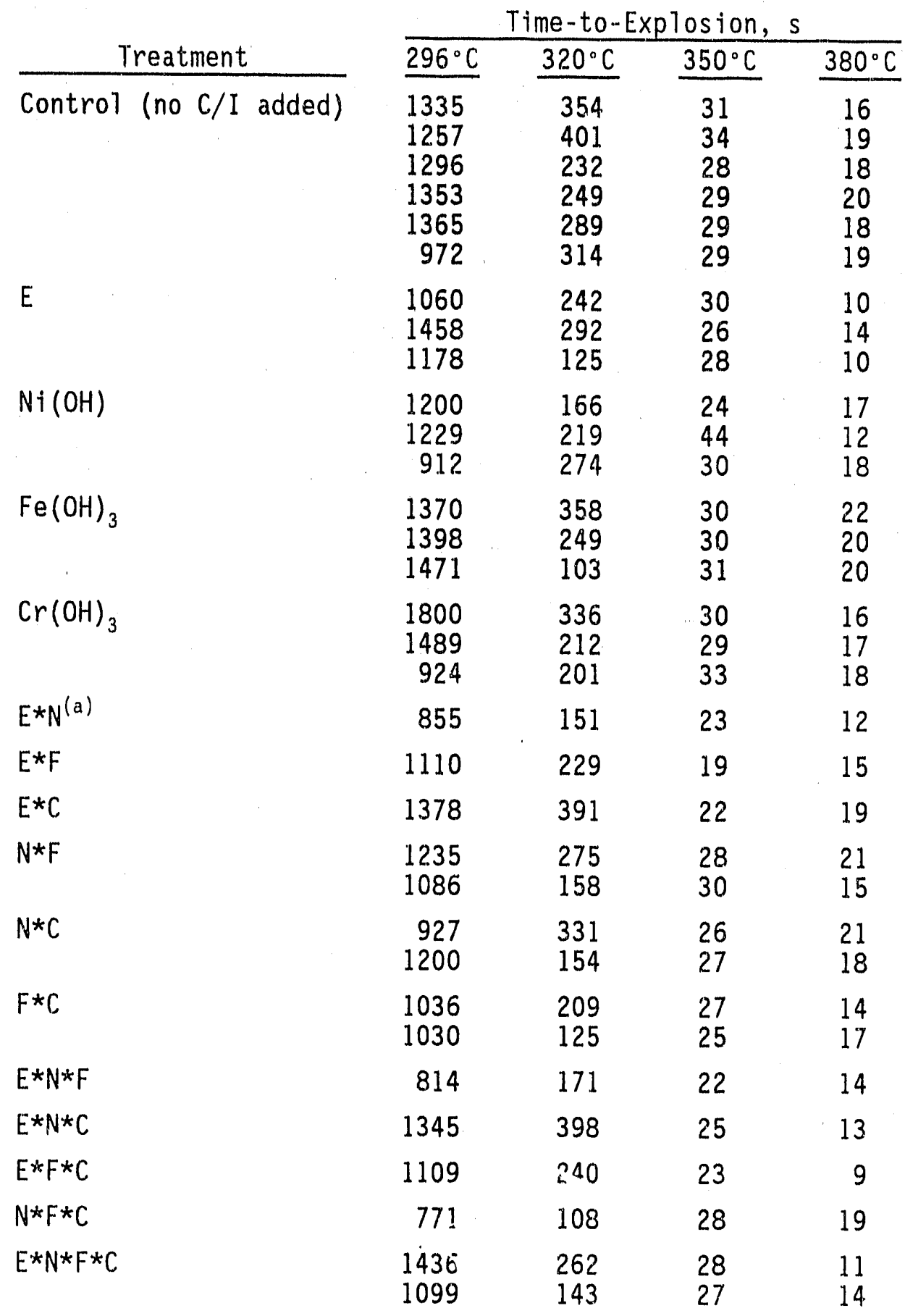

(a) $\quad E * N=E D T A+N i(O H)_{2}$ added to control mixture $\left[\mathrm{Na}_{2} \mathrm{NiFe}(\mathrm{CN})_{6}+\right.$ Equimolar $\left.\mathrm{NaNO}_{3}+\mathrm{NaNO}_{2}\right]$. 
APPENDIX B

PLOT OF 95\% CONFIDENCE LIMITS BASED ON DUNNETT DIFFERENCE FROM CONTROL 


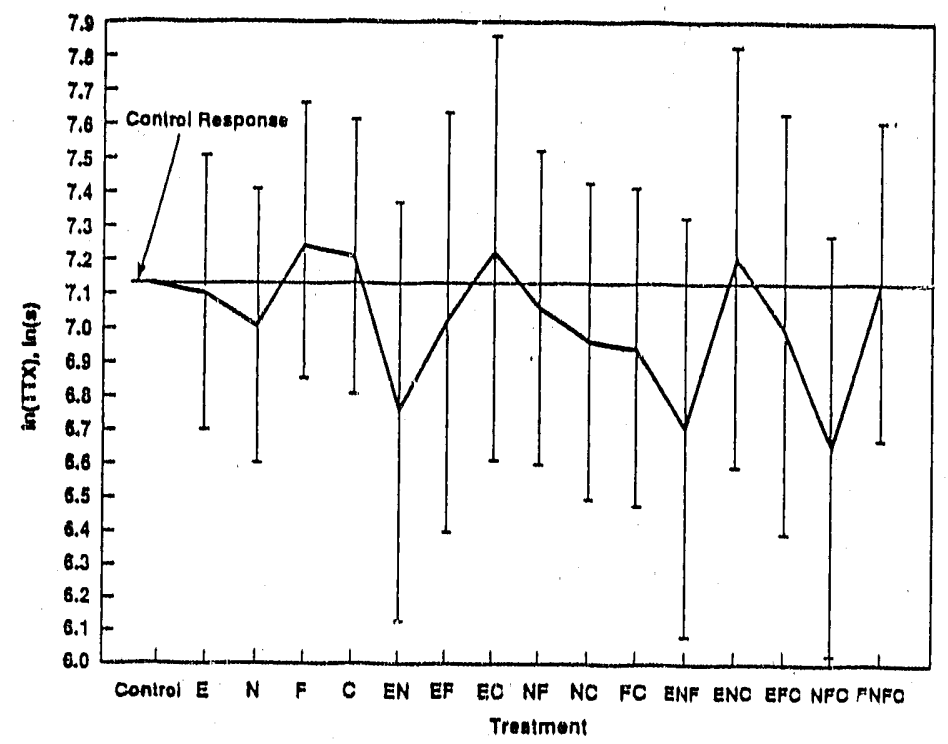

39201080.6

FIGURE B.1. Effect of Treatments on Mean $\ln \left(\right.$ TTX) at $296^{\circ} \mathrm{C}$ Including $95 \%$ Confidence Limits Based on Dunnett Difference from Control $\left[E=E D T A, N=N i(O H)_{2}, \mathrm{~F}=\mathrm{Fe}(\mathrm{OH})_{3}, \mathrm{C}=\mathrm{Cr}(\mathrm{OH})_{3}, \mathrm{EN}=\mathrm{EDTA}\right.$ plus $\mathrm{Ni}(\mathrm{OH})_{2}$ (as an example of treatment combinations)]

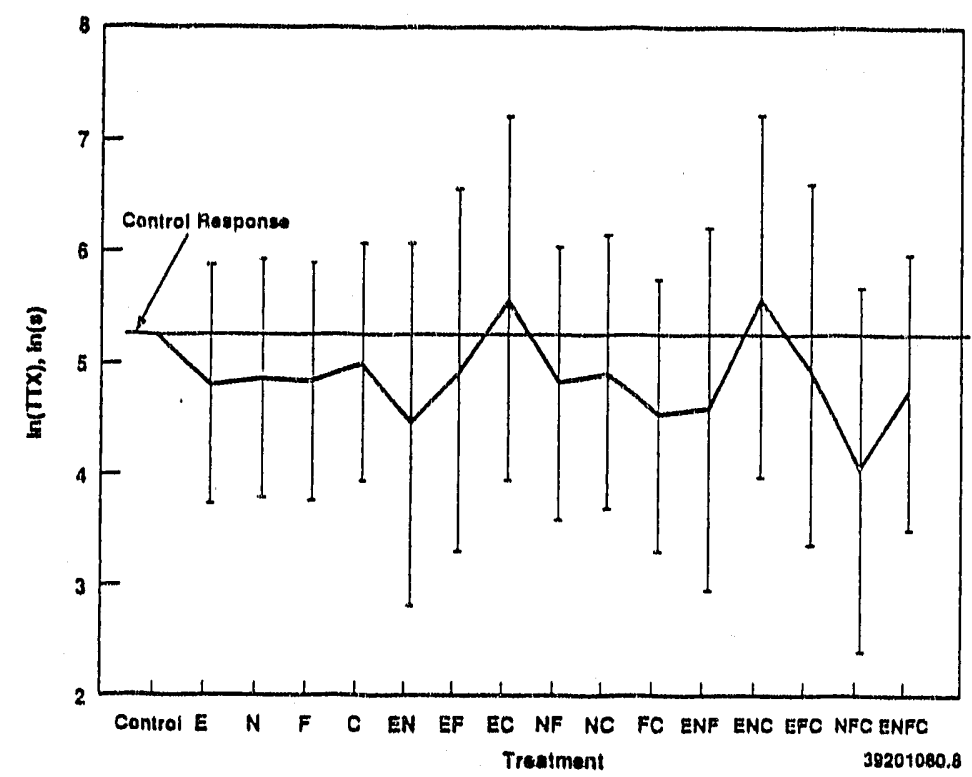

FIGURE B.2. Effect of Treatments on Mean $\ln \left(\right.$ TTX) at $320^{\circ} \mathrm{C}$ Including $95 \%$ Confidence Limits Based on Dunnett Difference from Control $\left[\mathrm{E}=\mathrm{EDTA}, \mathrm{N}=\mathrm{Ni}(\mathrm{OH})_{2}, \mathrm{~F}=\mathrm{Fe}(\mathrm{OH})_{3}, \mathrm{C}=\mathrm{Cr}(\mathrm{OH})_{3}, \mathrm{EN}=\mathrm{EDTA}\right.$ plus $\mathrm{Ni}(\mathrm{OH})_{2}$ (as an example of treatment combinations)]

B. 1 


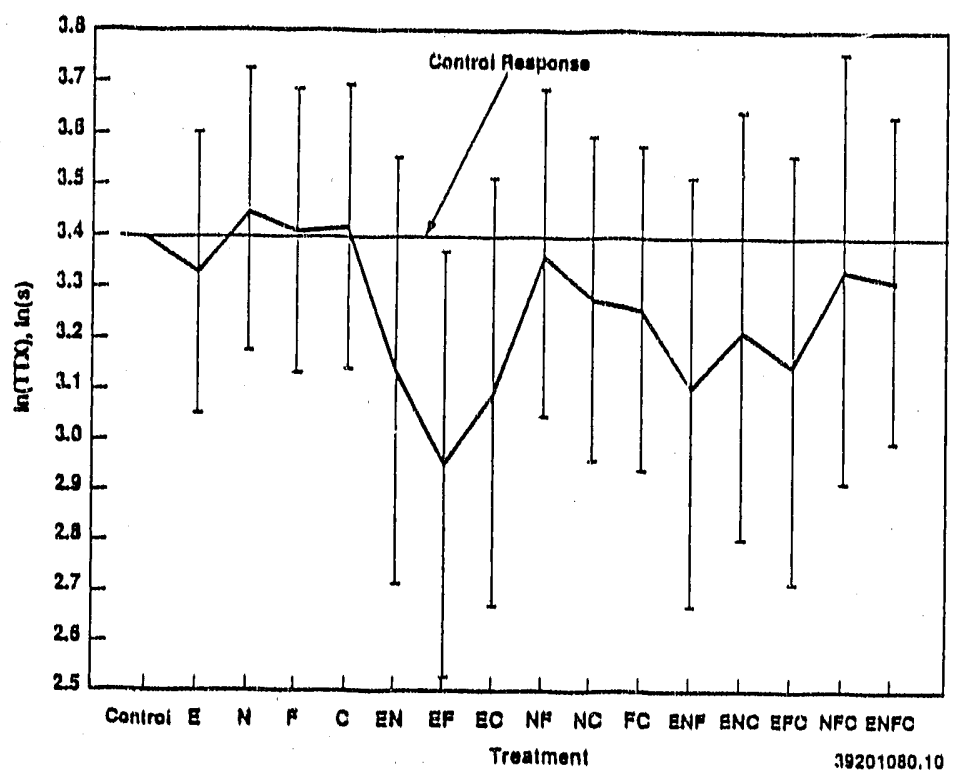

FIGURE B.3. Effect of Treatments on Mean $\ln (\mathrm{TTX})$ at $350^{\circ} \mathrm{C}$ Inciluding $95 \%$ Confidence Limits Based on Dunnett Difference from Control $\left[E=E D T A, N=\mathrm{Ni}(\mathrm{OH})_{2}, \mathrm{~F}=\mathrm{Fe}(\mathrm{OH})_{3}, \mathrm{C}=\mathrm{Cr}(\mathrm{OH})_{3}, \mathrm{EN}=\mathrm{EDTA}\right.$ plus $\mathrm{Ni}(\mathrm{OH})_{2}$ (as an example of treatment combinations)] 


\section{DISTRIBUTION}

No. of

Copies

\section{OFFSITE}

12 DOE/Office of Scientific and Technical Information

\section{J. C. Tseng \\ 7A-075/FORS}

U.S. Department of Energy 1000 Independence Avenue Washington, DC 20585

J. Antizzo

U.S. Department of Energy EM-351

Trevion II

Washingtor, DC 20585-0002

C. Terrell

U.S. Department of Energy, B1dg. 704-S

P.0. Box A

Atken, SC 29801

H. Walter

U.S. Department of Energy EM-343

Trevion II

Washington, DC 20585-0002

M. Walter

U.S. Department of Energy EM-35

Trevion II

Washington, DC 20845-0002

D. Wiffen

U.S. Department of Energy

EM-35

Trevion II

Washington, DC 20585-0002
No. of

Coptes

G. Woodal1

U.S. Department of Energy, MS-1139

785 DOE Place

Idaho Falls, ID 83402

E. C. Ashby

225 North Avenue

Boggs Chemistry. Butlding

Georgia Institute of

Technology

Atlanta, GA 30332

2 Brookhaven National Laboratory Building 129

Upton, NY 11973

ATTN: K. Bandyopadhyay

M. Reich

2 Westinghouse Savannah River

P.0. Box 616

Aiken, SC 29802

ATTN: N. E. Bibler

P. d'Entremont

$5 \quad$ Los Alamos National Laboratory, $\mathrm{M}-1$

P.0. Box 1163

Los Alamos, NM 87545

ATTN: H. H. Cady, MS-C920

J. C. Dal7man, MS-C920

T. Larson, MS-P915

E. D. Loughran, MS-C920

H. Sullivan, MS-K557

3 Oak Ridge National Laboratory

P.0. Box 2008

Oak Ridge, TiN 37831-6268

ATTN: D. Campbe 11, MS-6268

C. Forsberg, MS-6273

T. Kress, MS-8088

F. Carlson

6965 North, 5th West

Idaho Falls, ID 83401 
No. of

Coptes

2 SAIC

20030 Century Blvd.

Suite 201

Germantown, MD 20878

ATTN: R. Daniels

P. Hogroian

C. Abrams

1987 Virginta

Idaho Falls, ID 83404

M. First

295 Upland Avenue

Newton Highlands, MA 02161

C. Forsberg

MS-6273, P.0. Box 2008

Oak Ridge, TN 37831

E. J. Hart

2115 Hart Road

Port Angeles, WA 98362

E. P. Horwitz

Chemistry Division

Argonne National Laboratory

Argonne, IL 60439

2 WINCO

P.0. Box 4000

Idaho Falls, ID 83403-4000

ATTN: A. Hoskins, MS-5217

D. D. Siemer, MS-2207

B. Hudson

Lawrence Livermore National Laboratory, L-221

P.0. Box 808

Livermore, CA 94550

M. Kazimi

Room 24- 102

77 Massachusetts Avenue

Cambridge, MA 02139
No. of

Copies

P. Kiang

BDM, Trevion I, Suite 300

12850 Middlebrook Road

Germantown, MD 20874

D. Oakley

Los Alamos National Laboratory University of California, Suite 310

409 12th Street, SW

Washington, DC 20024-2188

D. Ploetz

West Valley Nuclear

Services Co.

P.0. Box 191, MS 305

West Valley, NY 14171-0191

J. Saveland

20030 Century Blvd., Suite 201

Germantown, MD 20874

G. Schmauch

Air Products \& Chemicals, Inc. 7201 Hamilton Blvd.

Allentown, PA 18195-1501

W. W. Schulz

727 Sweetleaf Drive

Wilmington, DE 19808

B. Schutte

EG\&G Idaho, Inc.

P.0. Box 1625

Idaho Falls, ID $83415-3940$

S. Slezak

Sandia National Laboratories, Division 6463

P.0. Box 5800

Albuquerque, NM 87185 
No. of

Coples

W. J. Thomson

Departmerit of Chemical

Engineering

Washington State University

Pullman, WA 99164

A. S. Veletsos

5211 Paisley

Houston, TX 77096

\section{FOREIGN}

J. Furrer

Karlsruhe Nuclear Center

7500 Karls suhe

GERMANY

Gerard Naud

Centre d'Etudes Nucleatres de Cadarache

13108 Saint Paul Lez

Durance Cedex

Cadarache FRANCE

\section{ONSITE}

12 DOE Richland Field office

G. H. Bracken, A6-80

R. F. Christensen, R4-04

J. M. Clark, A5-55

R. E. Gerton, A5-21

W. F. Hendrickson, N2-56

J. M. Herınig, A5-21

J. E. Newson, A6-80

G. Rosenwald, A5-21

W. A. Rutherford, A5-21

A. D. Toth, R4-04

B. J. Tucker, A4-35

Public Reading Room, Al-65
No. of

Coptes

37 West Inghouse Hanford Company

H. Babad, B3-68

D. G. Baide, R1-51

D. B. Bechtold, T6-50

M. L. Be11, T5-50

R. M. Black, R1-19

G. D. Blankenship, R1-62

R. J. B1 iss, B3-04

G. L. Borsheim, R2-11

W. F. Brehm, N2-01

W. W. Burk, L6-13

R. J. Cash, B3-68

J. L. Delchman, HO-03

G. L. Dunford, R1-51

K. A. Gasper, B3-68

J. M. Grigsby, B1-35

W. H. Hamiliton, R2-40

B. M. HanTon, R1-80

M. N. Is lam, R3-80

D. W. Jeppson, L5-31

J. M. Grigsby, B1-35

R. T. Kimura, R1-49

N. W. Kirch, R2-11

M. J. Klem, R2-12

W. D. Leggett, L5.04

L. D. Muhlestein, N1-28

E. H. Neflsen, R2-18

T. B. Powers, HO-31

J. G. Propson, R2-18

R. E. Raymond, R1-80

D. A. Reynolds, R2-11

W. G. Ruff, R2-53

M. H. Shannon, B1-35

D. D. Stepnewski, N1-31

D. J. Washenfelder, R1-43

D. D. Wodrich, R2-23

Waste Tank Safety Project.

Files, R1-28 (2) 
No. of

Copies

\section{Pacific Northwest Laboratory}

R. T. Allemann, K5-19

L.M.G. Ballou, P7-18

G. H. Bryan, P7-25

S. A. Bryan, P7-14

L. L. Burger, P7-25 (5)

T. H. Dunning, K2-18

R. T. Hallen, K2-12

M. S. Hanson, K1-51

B. M. Johnson, Jr., K1-78

J. W. Johnston, $K 7-34$

W. W. Laity, K2-15

D. K. Lemon, K2-28

M. A. Lilga, K2-12

J. D. Matheson, P7-25

L. G. Morgan, P8-07

G. F. Plepe1, K7-34

J.T.A. Roberts, K1-73

J. L. Ryan, P7-25

R. D. Scheele, P7-25 (5)

G. F. Schiefelbein, P8-38

L. J. Sealock, K2-10

J. C. Spanner, K2-31

D. M. Strachan, K2-44

R. W. Stromatt, P7-2?

J. M. Tingey, $P 7-25$

D. S. Trent, K1-82

H. H. VanTuy1, P7-25

Publishing Coordination

Technical Report Files (5) 

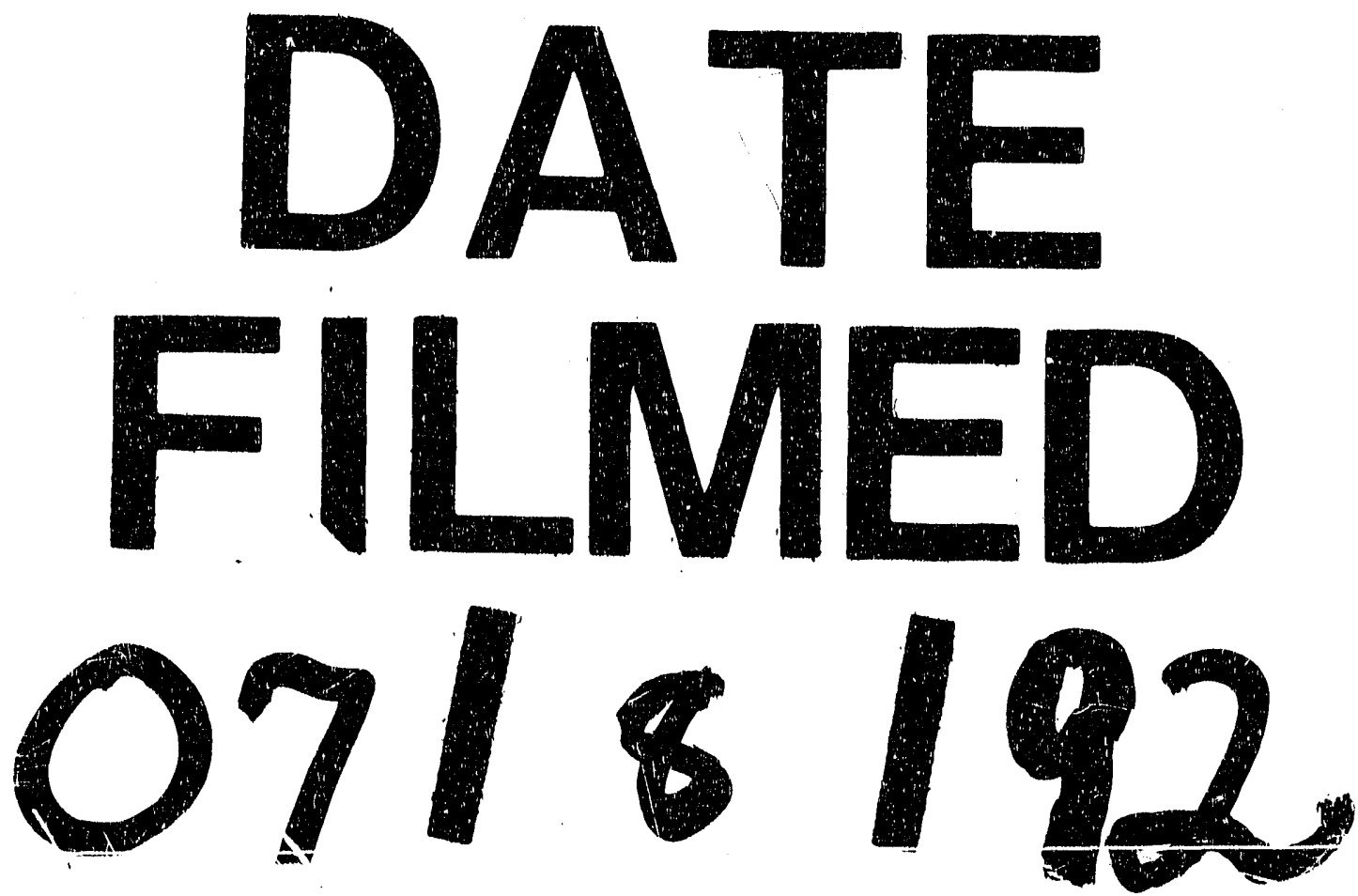
